\title{
The assesement of the shunt active filter efficiency under varied power supply source and load parameters
}

\author{
Yuriy Sychev ${ }^{1}$, Boris Abramovich ${ }^{2}$, Veronika Prokhorova ${ }^{3}$ \\ ${ }^{1,2}$ Electromechanical Department, Saint-Petersburg Mining University, Russian Federation \\ ${ }^{3}$ National Research University Higher School of Economics, Russian Federation
}

\begin{tabular}{|c|c|}
\hline Article Info & ABSTRACT \\
\hline Article history: & The results of theoretical and experimental studies on the problems of \\
\hline Received Oct 27, 2019 & $\begin{array}{l}\text { effective application of shunt active filters for power quality improvement } \\
\text { and electromagnetic compatibility ensuring were presented in this article. }\end{array}$ \\
\hline Revised May 16, 2020 & Based on the different theories and methods, the most effective and \\
\hline Accepted May 28, 2020 & $\begin{array}{l}\text { well-studied control algorithms of shunt active filters were determined and } \\
\text { analyzed to ensure their effective application in distributed generation }\end{array}$ \\
\hline Keywords: & $\begin{array}{l}\text { systems and combined power supply systems. Mathematical and computer } \\
\text { simulation models of shunt active filters with different control algorithms in }\end{array}$ \\
\hline Combined power supply & distributed generation systems and combined power supply systems were \\
\hline Distributed generation & developed. According to the results of mathematical modeling and computer \\
\hline Hybrid structure & simulation, the dependences were detected, reflecting the influences of \\
\hline Power quality & $\begin{array}{l}\text { internal and external parameters on the factors, determining the efticiency of } \\
\text { the correction of power quality indicators. The range of permissible changes }\end{array}$ \\
\hline Shunt active filter & $\begin{array}{l}\text { in the parameters of shunt active filters by saving the required efficiency } \\
\text { level of power quality correction was detected under varied power supply } \\
\text { system characteristics, load parameters and also in hybrid structures. } \\
\text { The adaptive algorithm of the shunt active filter functioning under varied } \\
\text { application conditions for automated power quality improvement is } \\
\text { developed on the basis of the obtained range and dependences. }\end{array}$ \\
\hline
\end{tabular}

Copyright $(2020$ Institute of Advanced Engineering and Science. All rights reserved.

\section{Corresponding Author:}

Yuriy Sychev,

Electromechanical Department,

Saint-Petersburg Mining University,

2, 21st Line, Saint-Petersburg, 199106, Russian Federation.

Email: ya_sychev@mail.ru

\section{INTRODUCTION}

It is undeniable that ensuring power quality improvement and electromagnetic compatibility is critical in centralized power supply systems, distributed generation systems, and combined power supply systems [1-4]. The main negative influences of the poor power quality level on electrical equipment and power supply systems are well-known and have been studied in detail [5-10]. In particular, this problem has become more significant considering the intensive development of technologies and the principles of distributed generation from alternative and renewable power sources and combined power systems, where both centralized and distributed sources work in parallel mode.

Nowadays, there is a set of different devices and solutions for power quality improvement. Among them it is reasonable to indicate passive and active devices [5]. Passive devices are not so effective in the conditions of combined power systems [7]. Active devices, such as the shunt active filters, are able to improve power quality in the adaptive mode by means of the special control methods and algorithms [9]. But in case of the shunt active filters application in conditions of variable type of power source and connected load there is the problem of proper selection of the main parameters of these filters for saving the required power quality level, especially in the combined power systems. Also it is very important to 
choose the optimal control method of shunt active filter for performing the adaptive power quality improvement mode. Besides an active filter is an expensive and multifunctional device for several power quality indicators improvement. The efficiency level of such improvement depends on the control method type and external factors [11-16].

Hereby in conditions of the combined power systems with variable source and load type and parameters there are the following main problems of the efficient shunt active filter application for power quality improvement [17-20]:

- The great amount of control methods for active filters, with some advantages and disadvantages, which have been studied and proved only for the special application conditions and limitations.

- The opportunity to improve several power quality indicators by one multifunctional device, such as the active filter, is limited by the absence of the universal adaptive control algorithm.

- The high cost of active filter, which can be decreased by the proper selection of the filter's main parameters or their decreasing in the permitted ranges according to the application conditions.

The complex solution of the mentioned problems is proposed in this paper by the developing of the universal adaptive algorithm of the shunt active filter functioning in conditions of the combined power systems with variable source and load parameters. The basis of the developed algorithm is the obtained dependences of the power quality improvement indicators from the internal and external parameters for the different types of active filter control method. The developed algorithm and the obtained dependences are new in the developing of the active filters application theory and practice.

The contributions of the proposed solution in the theory and practice of active filters application are the following:

- The improvement of shunt active filter performance in conditions of the combined power supply systems, when parameters of the source (centralized or distributed) varies in the wide range as well as parameters of the connected load in the case of changing power supply mode during failures in centralized network.

- The possibility to effectively realize the multifunctional device on the basis of one shunt active filter for improvement of several power quality indicators.

- The possibility of adaptive changing of shunt active filter parameters according to the given set of the internal and external factors with saving the required power quality improvement performance.

The indicated solution can be achieved due to the following research method.

\section{RESEARCH METHOD}

The main idea of the proposed research method is to detect and analyze the performance of different control ways of shunt active filter under variation of external and internal factors. Here the external factors are the parameters and characteristics of power source and connected load, and the internal factors are the parameters and characteristics of shunt active filter. The main purpose of such method is to determine the optimal control way of shunt active filter under the given set of different factors, when this filter is used as a stand-alone device or a part of multifunctional device for power quality improvement. The proposed research method consists of three main stages.

\subsection{The first stage}

The first stage is the selection of character control ways from all plenty of the existing methods and theories for the further research. According to the results of numerous theoretical and experimental studies [7, 8, 21-26], the ways developed for the determination and correction of power quality indicators for shunt active filter control may be divided into three main groups [27-30]:

- Ways based on discrete (DFT) and fast Fourier (FFT) transformations [31-35].

- Ways that extract the reference values of current or voltage using the theories and methods of current physical components (CPC) [22, 23, 36].

- Ways based on phase transformations in different reference frameworks ( $\alpha \beta$, dq, Clarke transformations) [25].

- Ways that use the theories and methods of instantaneous power components [24, 27] (p-q theory), developed by H. Akagi.

- Fuzzy logic ways [37, 38].

All of the mentioned ways have been described, studied, and proved [22-36] under special power source and connected load conditions, but there are no results on the comparative analysis of the efficiency levels of these ways under different power source and connected load conditions. The potential results of such analysis are determination of the main stage of the theory of structural and parametric synthesis of electrical complexes for power quality improvement on the basis of active and passive filters. Also, such 
analysis is necessary because an active filter is a controllable part of any hybrid structure. That is why the main method of modeling and simulation is the comparative analysis of the mentioned ways under varied power source, connected load, and active filter conditions.

For this purpose, a simulation model of the power supply system with linear and non-linear loads was developed using Matlab Simulink software. Also, this model contains the shunt active filter with different control ways. For simulation purposes, the following widespread ways for shunt active filters control, which have been proven for application, were selected [22-36]:

- A way based on the p-q theory with a special regulator of the voltage of the storage capacitor (way \#1).

- A way based on the phase transformations in the reference framework $\alpha \beta$ (way \#2).

- A way based on the CPC theory with DFT or FFT (way \#3).

- A way based on the phase transformations in the reference framework dq (way \#4).

- A way based on the p-q theory without the special voltage regulator of the storage capacitor (way \#5).

The initial rated parameters of the shunt active filter for each control way were the same.

The indicated control ways have some limitations and assumptions. According to the results from experimental studies and computer simulations [25, 34, 35] control ways \#2 and \#4 demonstrate the maximum efficiency level under conditions of traditional centralized power supply systems with little value placed on internal impedance and short-circuit power. Control way \#3 can effectively eliminate harmonics under a constant current level, which is consumed by the connected non-linear load. As shown in some publications [26, 39], control ways \#1 and \#5 have maximal efficiency only under conditions of three-phase three-wire systems. Fuzzy logic control ways [37, 38] are the modern class of active filters control algorithms and their efficiency is defined by the special features of power source and connected load. That is why the area of such ways application is limited.

All parameters of the developed model, including the parameters of the source, power line, load node, and shunt active filter, were the same for each studied control way. These parameters were selected according to the results of experimental research [7,8]. The initial parameters of the shunt active filter were set according to the optimal relationship between the rated current of the non-linear load $I_{n n}$ and the rated current of the filter $I_{\text {saf }}$ detected during experimental research [7, 8] using the criterion of harmonic minimization:

$$
I_{s a f}=(0.5-0.7) I_{n n}
$$

During modeling, the parameters and settings of the regulators of the active filter control system for each studied control way were unchanged.

\subsection{The second stage}

The second stage is the indication of the simulation process sequence, which includes the following steps:

- A comparative analysis of the efficiency level of these control ways when changing the correlation $\beta$ of active powers of non-linear (NN) PNN and linear (LN) PLN loads at the point of common coupling (PCC). The correlation factor $\beta$ is calculated as follows:

$$
\beta=\frac{P_{N N}}{P_{N N}+P_{L N}} \cdot 100 \%
$$

- A comparative analysis of the efficiency level of these control ways when changing the internal reactance of the power source Xs [39].

- A comparative analysis of the efficiency level of these control ways when changing the reference voltage of the storage capacitor Udc, the inductance of the output choke L, and the capacitance of the storage element Cdc of the shunt active filter.

- The comparative analysis of the efficiency level of these control ways when changing the point of connection of the shunt active filter's primary current and voltage sensors at the PCC, at the non-linear load terminals, and at the source side, as shown in Figure 1.

In the proposed research method, the parameters $C_{d c}, L$, and $U_{d c}$ are considered as the internal factors and the parameters $X_{s}$ and $\beta$ are considered as the external factors during the analysis of the shunt active filter behavior. 


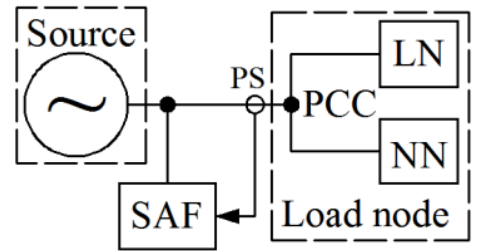

a)

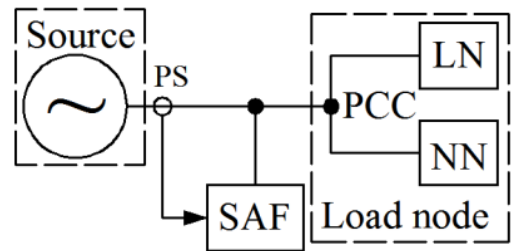

b)

Figure 1. The point of connection of the primary sensors (PS) of the shunt active filter (SAF), (a) at the point of common coupling (PCC); (b) at the source side

\subsection{The third stage}

The third stage is the detection of the efficiency indicators, which reflects the degree of power quality improvement due to application of shunt active filter with different control ways. For the evaluation of the shunt active filter efficiency with different control ways, the following indicators were considered. The indicator of the degree of voltage total harmonic distortion factor $\left(T H D_{U}\right)$ correction was determined as follows:

$$
\Delta T H D_{U}=\frac{T H D_{U}^{\prime}-T H D_{U}^{\prime \prime}}{T H D_{U}^{\prime}} \cdot 100 \%
$$

In (3), $T H D_{U}{ }^{\prime}$ and $T H D_{U}^{\prime \prime}$ are the total harmonic distortion factors [40] for voltage at the PCC before and after shunt active filter connection. A similar indicator is applicable for the evaluation of the degree of current total harmonic distortion factor $T H D_{I}$ correction $\left(\triangle T H D_{I}\right)$ and also for the degree of correction of the voltage $\left(\Delta k_{U 2}\right)$ and current $\left(\Delta k_{I 2}\right)$ unbalances factors [41] for the negative sequence components of voltage $U_{n s 2}$ and current $I_{n s 2}$. One should note here that the voltage unbalance factor $k_{U 2}$ [41] for the negative sequence components is determined and regulated using the Russian national standard GOST 32144-2013 of power quality [41] according to the following:

$$
k_{U 2}=\frac{U_{n s 2}}{U_{p s 1}} \cdot 100 \%
$$

where $U_{n s 2}$ and $U_{p s 1}$ are the negative and positive voltage sequence components, respectively. The current unbalance factor $k_{12}$ can be determined similarly to equation (4) for the evaluation of the influence of the load unbalance on the power quality level. The indicator of the degree of correction of voltage dips and deviations $\Delta U$ is determined according to the following:

$$
\Delta U_{s}=\frac{U_{1}-U_{2}}{U_{r}} \cdot 100 \%=\frac{\left(U_{r} \pm \Delta U_{1}\right)-\left(U_{r} \pm \Delta U_{2}\right)}{U_{r}} \cdot 100 \%,
$$

where $U_{r}$ is the rated value of the network voltage, and $U_{1}$ and $U_{2}$ are the network voltages before and after shunt active filter installation. The indicator $\Delta U_{s}$ helps to determine the efficiency of correction of both positive and negative voltage deviations $[42,43]$.

The indicator, which reflects the degree of decrease in the current consumed by the load node due to elimination of the reactive and non-active power components, is determined as follows:

$$
\Delta I_{l}=\frac{I_{1}-I_{2}}{I_{1}} \cdot 100 \%
$$

where $I_{1}$ and $I_{2}$ are the currents consumed by the load node before and after shunt active filter installation.

Hence, the values of the mentioned efficiency indicators will show the features of each studied control way when the shunt active filter application under the different set of internal and external factors [44-47]. Hereby the all stages of the presented research method allow obtaining the required regularities, assessing the presented indicator's values and developing the adaptive algorithm of shunt active filter control under variation of external and internal factors. 


\section{RESULTS}

The dependences of the indicators of the efficiency of power quality correction by means of the shunt active filter with different control ways (\#1-5) at the PCC determined from the variation of the internal reactance of the power source $X_{s}$ are presented in the Figure 2. The similar dependences were obtained for the variation of other factors $C_{d c}, L, U_{d c}$ and $\beta$. In the Table 1 the results of power quality indicators correction by means of the shunt active filter with different control ways are presented for the initial parameters of power source, load and filter.
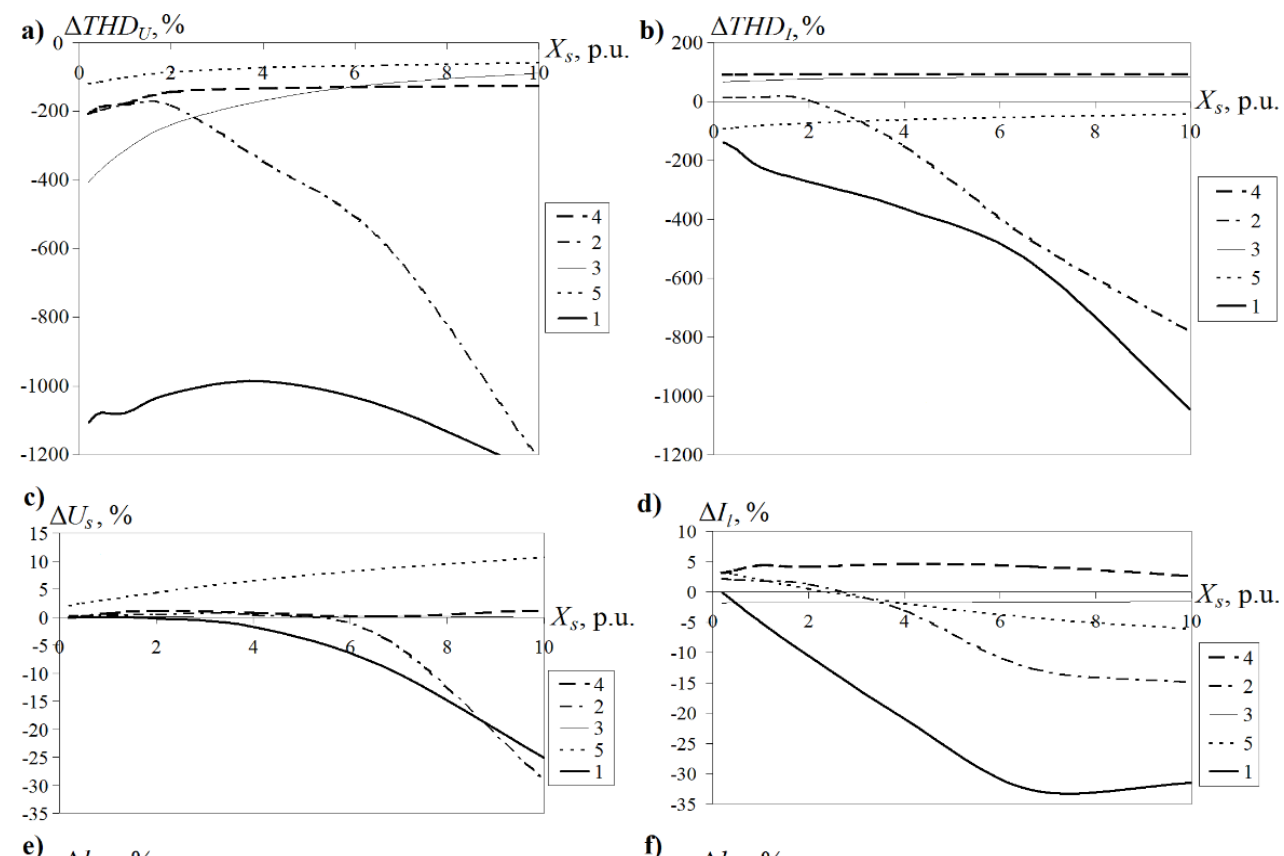

d)
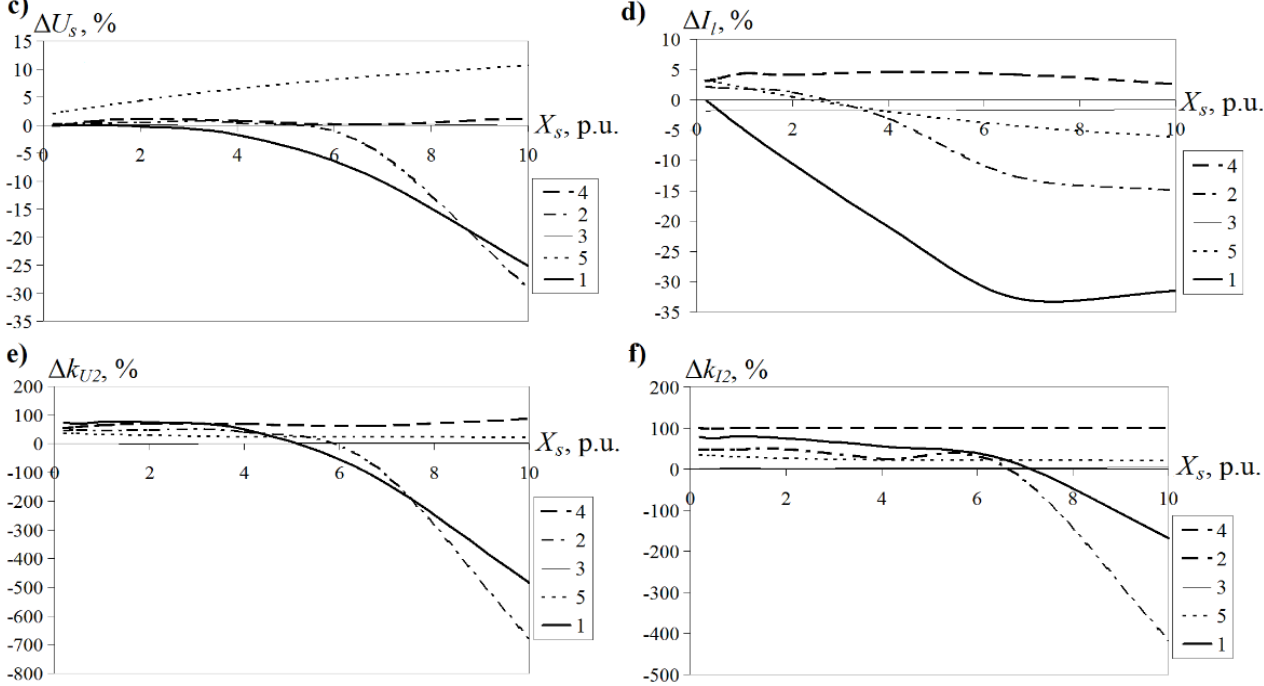

Figure 2. The dependences of the indicators of the efficiency of power quality correction at the PCC determined from the variation of the internal reactance of the power source $X_{s}$, (a) $\triangle T H D_{U}$; (b) $\triangle T H D_{I}$;

$$
\text { (c) } \Delta U_{s} ; \text { (d) } \Delta I_{l} \text {; (e) } \Delta k_{U 2} \text {; (f) } \Delta k_{i 2}
$$

Table 1 . The results of power quality indicators correction

\begin{tabular}{ccccccc}
\hline Algorithm & $\Delta U_{s}, \%$ & $\Delta T H D_{U}, \%$ & $\Delta I_{l}, \%$ & $\Delta T H D_{I}, \%$ & $\Delta k_{I 2}, \%$ & $\Delta k_{U 2}, \%$ \\
\hline$\# 1$ & -0.10 & -1078.6 & -5.00 & 26.37 & 79.06 & 75.61 \\
$\# 2$ & 0.39 & -180.66 & 1.83 & 41.29 & 47.64 & 46,34 \\
$\# 3$ & 0.07 & -313.79 & -1.78 & 80.58 & 2.27 & 0.00 \\
$\# 4$ & 0.62 & -192.59 & 4.35 & 93.67 & 99.13 & 63.41 \\
$\# 5$ & 3.15 & -101.23 & 2.03 & -40.81 & $30 . .89$ & 32.93 \\
\hline
\end{tabular}

According to the results of the simulation and during the analysis of the obtained regularities the following main conclusions were made:

- None of the studied algorithms allow the voltage harmonics from the source to be corrected efficiently when changing internal and external factors.

- The most effective algorithm for the stable correction of current harmonics, unbalance, and non-active power components is the method based on the phase transformations in the reference framework dq (way \#4). The satisfactory level of the efficiency of this algorithm is fully saved in a whole range of internal impedances of the source and internal parameters of the shunt active filter. 
- The most effective algorithm for the stable correction of voltage dips and deviations is the method based on phase transformations that uses p-q theory without the special regulator of voltage of the storage capacitor (way \#5). A satisfactory level of efficiency of this algorithm is fully conserved across the whole range of internal impedances of the source.

- None of the studied algorithms allow the voltage unbalance of the source to be corrected efficiently when changing the internal and external factors across the whole range.

- In areas with small internal impedance values of the source (traditional centralized power supply systems), ways \#2, \#3, and \#4 possess the maximal current harmonic correction efficiency.

- In areas of small internal impedance values of the source (traditional centralized power supply systems), all studied algorithms allow the voltage unbalance and deviations and the current unbalance of the load to be corrected, with the exception of way \#3.

- Under conditions of variation in the correlation between the rated active powers of the linear and non-linear loads $\beta$ in the PCC, the most efficient current harmonic correction is shown by ways \#3 and \#4.

- In areas with large internal impedance values of the source (distributed generation systems), the greatest efficiency in the elimination of current harmonics and non-active current components is shown by way \#4.

- Changes in the capacitance of the storage capacitor of the shunt active filter within the set range do not significantly influence the indicators of the efficiency of the power quality correction for ways \#2, \#3, \#4.

- The increase in the inductance of the output chokes of the shunt active filter allows the efficiency of the voltage and current harmonic correction to be improved for all algorithms. However, for way \#2, the significant increase in such inductance leads to a sharp decrease in the efficiency of the voltage and current unbalance correction, the voltage dips elimination, and the non-active power components compensation.

- Changes in the reference voltage for the storage capacitor of the shunt active filter significantly influence the indicators of the efficiency of power quality improvement only in the case of way \#4.

- The efficiency level of the shunt active filter in the case of primary sensors connection at the PCC is better on the whole than in the case of primary sensors connection at the source side. However, when way \#4 is applied, the placement of primary sensors at the source side allows the maximal level of the efficiency of voltage deviation correction to be reached compared with other algorithms and with the placement of such sensors at the PCC.

It must be noted that the obtained results help to properly select a control way for shunt active filter control according to the given conditions of the filter's installation and application [48-52]. The obtained results have given an opportunity to develop the adaptive algorithm of the shunt active filter functioning under varied application conditions for automated power quality improvement. The developed adaptive algorithm is presented in the Figure 3. This algorithm allows shunt active filter to be integrated into the automated monitoring and control systems as one of the main elements, taking part in the forming of informational and control interactions.

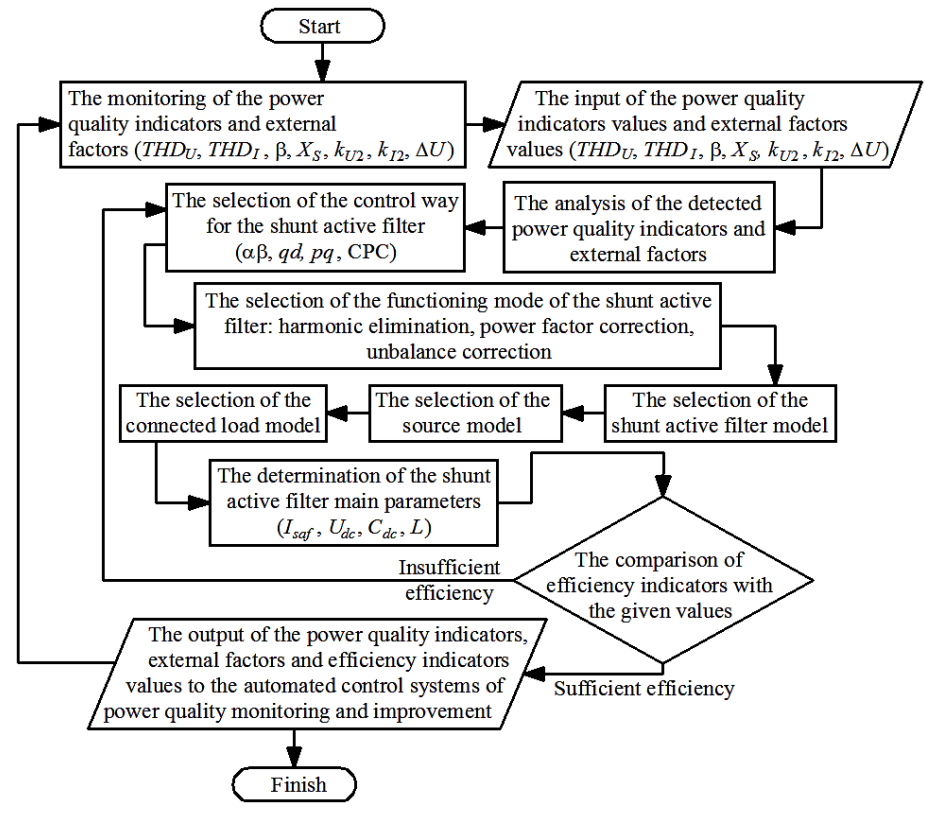

Figure 3. The adaptive algorithm of the shunt active filter functioning under varied application conditions for automated power quality improvement 


\section{DISCUSSION}

The first thing that needs to be said is that the problem of power quality improvement by means of active, passive, and hybrid filters has been considered in many scientific publications. In these publications, authors have focused on the structure of hybrid filters, the control algorithm of the shunt or series active filters, and the evaluation of the efficiency of certain structures under specified conditions of the power source, network, and connected load [1]. From a theoretical point of view, such research is very useful and may be used as the basis for more significant research.

Here, special attention should be paid to modern trends in electrical energy technologies. The first trend is the complex application of distributed generation technologies on the basis of alternative and renewable energy sources such as wind farms, solar stations, and micro turbine installations working on natural or associated petroleum gas. The second trend is the technologies and methods used for the parallel functioning of centralized and distributed sources in the framework of combined power supply systems $[39,42,43]$. The third trend is the usage of active converters as the main elements of electrical complexes of alternative and renewable sources. The fourth trend is the implementation of several different functions in the framework of one active converter, active filter, or hybrid filter. According to the mentioned trends, for active converters and filters to be presented as parts of an electrical complex of a power source, as elements of a distribution network (e.g., UPFC) [12], and as parts of a connected load, it is necessary to have unified theoretical and methodical propositions for the development and application of such converters and filters under different conditions. Also, we cannot ignore the fact that the centralized and distributed power supply systems possess different parameters and characteristics which must be taken into account in the selection of structures, key parameters, and control algorithms of active converters, active, passive, and hybrid filters, and their applications $[33,34]$. That is why it is necessary to research the behavior of active and hybrid filters under varied conditions of internal impedance of the power source when we need to change the power supply mode from centralized to distributed and vice versa in emergency cases in combined power supply systems.

Another thing about this method is that there is a great number of different control algorithms that can be used for active converters and filters as controllable devices, especially for shunt active filters. These algorithms have been created, described, and proven in many scientific publications for specified conditions of its application [22]-[36]. Besides, some algorithms are improved versions of previous similar algorithms with no significant and minimal changes. That is why it is necessary and reasonable to give a general classification of all existing and proven algorithms of active filter control and to extract the most effective and fundamental ones. On the assumption of application conditions of active filters as standalone devices or as part of a hybrid structure in centralized, distributed, and combined power supply systems, it is necessary to research the efficiency levels of the extracted algorithms. The results of such studies allow the methodology for the proper selection of the control method for active filters to be created. Also, these results are a key part of the theory of structural and parametric synthesis of electrical complexes for power quality improvement on the basis of active and passive filters [37-44].

It is undeniable that any hybrid filter structure is intended to decrease the rated parameters of the active part by means of the properly tuned passive filters, because the active part is the most expensive part. That is why it is reasonable to detect the degree of this decrease under different application conditions and for the most widespread types of hybrid structures [35, 43]. Also, one of the main ideas of the presented paper is to show the range in which the parameters $C_{d c}, L$, and $U_{d c}$ can be changed when the active filter is the part of the hybrid structure or when it is working under combined power supply conditions when the internal impedance of the power source is changed [45-48].

In addition, when we select the parameters $C_{d c}, L$, and $U_{d c}$ for specific operating conditions, we do not take into account the fact that these conditions may change (due to failures in power systems, faults, and changes in the power source). That is why it is useful and reasonable to know the ranges of selection of the parameters $C_{d c}, L$, and $U_{d c}$ during the application of the active filter under complicated conditions without resetting the regulators' parameters and while saving the filters' operating efficiency. An active filter is quite an expensive device and it should be rated to work not only under special conditions but under a wide range of conditions with minimal changes in $C_{d c}, L$, and $U_{d c}$ and regulator settings. Also, the presented ranges of selection of the parameters $C_{d c}, L$, and $U_{d c}$ help us to detect the possible decrease in the cost of the active filter while retaining the filters' operating efficiency [49-52].

Also, in case of adjustment of the active filter on-side, it is very difficult to chose and tune the parameters of regulators if the real parameters of the power system differ from those designed. This fact has been proven during our experimental research experience [7, 8]. The above-mentioned facts illustrate a very important, serious, and actual problem of the theory and methodology of structural and parametric synthesis of electrical complexes for power quality improvement on the basis of active and passive filters [43]. The presented results are only one of the several stages of this theory and methodology. The main 
subject of future research in this area is the development of theory and methodology for the complex integration of multifunctional active converters and active and passive filters in the structure of combined power supply systems, working on the basis of parallel functioning of centralized and distributed sources.

\section{CONCLUSION}

The results of theoretical and experimental research in the area of the proper selection of control algorithm and main parameters of the shunt active filter under variation of the characteristics of power source and connected load were presented in this article. The presented results are intended to aid in the design and development of the theory and methodology of the selection of the structure, content, functional mode, key parameters, and control algorithm of the electrical complexes related to power quality improvement on the basis of active and passive filters. Using mathematical modeling and computer simulation, the dependences of the indexes of power quality correction efficiency under varied external and internal factors were obtained. These dependences should be considered as the key stage of the design and development of the theory and methodology of structural and parametric synthesis of the electrical complexes related to power quality improvement on the basis of active and passive filters.

The main contribution of the results presented in this paper is the determination of the ranges in which the main parameters of shunt active filters may be changed in the framework of hybrid structures and under conditions of variation in the power supply system characteristics while retaining the required efficiency level for power quality indicator correction. These ranges also allow the cost of the active part, which is the most expensive part of any hybrid structure, to decrease. The detected dependences and proposed adaptive algorithm are intended to help properly choose the structure and control way of shunt active filter under variable power source parameters and connected load characteristics. Also the proposed adaptive algorithm allows integrating the shunt active filter into the complex systems of automated power quality control, monitoring and improvement.

\section{REFERENCES}

[1] S. R. Salkuti, "Challenges, Issues and Opportunities for the Development of Smart Grid," International Journal of Electrical and Computer Engineering (IJECE), vol. 10, no. 2, pp. 1179-1186, 2020.

[2] C. Jung, P. Ray, S. R. Salkuti, “Asset Management and Maintenance: a Smart Grid Perspective," International Journal of Electrical and Computer Engineering (IJECE), vol. 9, no. 5, pp. 3391-3398, 2019.

[3] C. M. Thuyen, "A New Design Algorithm for Hybrid Active Power Filter," International Journal of Electrical and Computer Engineering (IJECE), vol. 9, no. 6, pp. 4507-4515, 2019.

[4] V.Z. Manusov, P.V. Matrenin, N. Khasanzoda, "Swarm Algorithms in Dynamic Optimization Problem of Reactive Power Compensation Units Control," International Journal of Electrical and Computer Engineering (IJECE), vol. 9, no. 5, pp. 3967-3974, 2019.

[5] N. Cherkaoui, et al., "Optimal Location and Reactive Power Injection of Wind Farms and SVC's Units Using Voltage Indices and PS," International Journal of Electrical and Computer Engineering (IJECE), vol. 9, no. 5, pp. 3407-3414, 2019.

[6] S. A. Pizarro, J. E. Candelo-Becerra, F. E. Hoyos Velasco, "Optimal Parameters of Inverter-Based Microgrid to Improve Transient Response," International Journal of Electrical and Computer Engineering (IJECE), vol. 10, no. 1, pp. 637-650, 2020.

[7] S. Narasimha, S. R. Salkuti, "An Improved Closed Loop Hybrid Phase Shift Controller for Dual Active Bridge Converter," International Journal of Electrical and Computer Engineering (IJECE), vol. 10, no. 2, pp. 1169-1178, 2020.

[8] H. Mahieddine, et al., "Developing a Grid-Connected DFIG Strategy for the Integration of Wind Power with Harmonic Current Mitigation," International Journal of Electrical and Computer Engineering (IJECE), vol. 9, no. 5, pp. 3905-3915, 2019.

[9] S.P. Litran, et al., "Comparative Analysis of Compensation Strategies for Series APF Based on the Electric Power Dual Formulation," Proceedings of the 11th IEEE International Conference on Compatibility, Power Electronics and Power Engineering, CPE-POWERENG 2017, vol. 1, pp. 199-204, 2017.

[10] S.P. Litran, P. Salmeron, "Electromagnetic Compatibility Analysis of a Control Strategy for a Hybrid Active Filter," Electric Power Systems Research, vol. 144, pp. 81-88, 2017.

[11] J. Prieto Thomas, et al., "Practical Evaluation of Unbalance and Harmonic Distortion in Power Conditioning," Electric Power Systems Research, vol. 141, pp. 487-499, 2016.

[12] A. Perez Valles, P. Salmeron Revuelta, "A New Distributed Measurement Index for the Identification of Harmonic Distortion and/or Unbalance Sources Based on the IEEE Std. 1459 Framework," Electric Power Systems Research, vol. 172, pp. 96-104, 2019.

[13] J. P. Thomas, et al., "Assessment on Apparent Power Indices with Hybrid Active Power Filters," Proceedings of the 11th IEEE International Conference on Compatibility, Power Electronics and Power Engineering, vol. 1, pp. 181-186, 2017. 
[14] P. S. Revuelta, S. P. Litran, and J. P. Thomas, "Active Power Line Conditioners: Design, Simulation and Implementation for Improving Power Quality,” Elsevier: Amsterdam, Holland, pp. 314-317, 2016.

[15] S. P. Litran, and P. Salmeron, "Design Criteria of a Control Strategy for Hybrid Power Filters Based on Current and Voltage Detection," International Transactions on Electrical Energy Systems, vol. 25, no. 3, pp. 419-432, 2015.

[16] A. Vinayagam, et al., "Power Quality Analysis in Microgrid: an Experimental Approach," J. Power Energy Eng, vol. 4, pp. 17-34, 2016.

[17] A. E. Kozyaruk, A.M. Kamyshyan, "Improving the Energy Efficiency of the Electromechanical Transmission of an Open-Pit Dump Truck," Journal of Mining Institute, vol. 239, pp. 576-582, 2019.

[18] Y. Shklyarskiy, et al., "Distortion load identification based on the application of compensating devices," Energies, vol. 13 , no. $6,2020$.

[19] F. H. Gandoman, et al., "Review of FACTS Technologies and Applications for Power Quality in Smart Grids with Renewable Energy Systems,” Renew. Sustain. Energy Rev., vol. 82, pp. 502-514, 2018.

[20] B. N. Abramovich, et al., "The Shunt Active Filters Implementation for Power Quality Increasing in Electrical Networks of Priobskoye Deposit," Neftyanoe khozyaystvo - Oil Industry, vol. 6, pp. 130-132, 2011.

[21] B. N. Abramovich, et al., "Power Factor Correction by Means of Active Filter in Networks of Oil and Gas Enterprises," Neftyanoe khozyaystvo - Oil Industry, vol. 5, pp. 88-90, 2008.

[22] Y. V. Gulkov and D. A. Ustinov, "Electric Power Quality Distortions Influencing Oil Processing Plant Parameters and Characteristics," International Journal of Applied Engineering Research, vol. 12, no. 9, pp. 2027-2030, 2017.

[23] Y. L. Zhukovskiy, et al., "The Prediction of the Residual Life of Electromechanical Equipment Based on the Artificial Neural Network," IOP Conference Series: Earth and Environmental Science, vol. 87, no. 3, 2017.

[24] S.V. Baburin and M.S. Kovalchuk, "Analysis of Power Supply Systems Reliability for Gas Pumping Compressor Stations," Proceedings of the 2018 IEEE Conference of Russian Young Researchers in Electrical and Electronic Engineering, pp. 566-569, 2018.

[25] S. Dutta, et al., "Unified Power Flow Controller Based Reactive Power Dispatch Using Oppositional Krill Herd Algorithm," Int. J. Electr. Power Energy Syst., vol. 80, pp. 10-25, 2016.

[26] C. Yadaiah, et al., "Effect of Network Reconfiguration on Power Quality of Distribution System," Int. J. Electr. Power Energy Syst., vol. 83, pp. 87-95, 2016.

[27] V. Veera Nagi Reddy, D.V Ashok Kumar, V. Reddy Kota, "A multilevel UPQC for voltage and current quality improvement in distribution system," International Journal of Power Electronics and Drive Systems (IJPEDS), vol. 10, no. 4, pp. 1932-1943, 2019.

[28] M. Ochoa-Gimenez, et al., "Comprehensive Control for Unified Power Quality Conditioners,” J. Mod. Power Syst. Clean Energy, vol. 5, pp. 609-619, 2017.

[29] A. Movahedi, et al., "Designing SSSC, TCSC, and STATCOM Controllers Using AVURPSO, GSA, and GA for Transient Stability Improvement of a Multi-Machine Power System with PV and Wind Farms," Int. J. Electr. Power Energy Syst., vol. 106, pp. 455-466, 2019.

[30] M. Ahmad, S. Kirmani, "Performance Analysis of LMS Based Control Algorithm for Power Quality Improvement in Three Phase Grid Connected System for Linear/Non-Linear Load," International Journal of Power Electronics and Drive Systems (IJPEDS), vol. 10, no. 4, pp. 1944-1950, 2019.

[31] W. U. K. Tareen and S. Mekhielf, "Three-Phase Transformerless Shunt Active Power Filter with Reduced Switch Count for Harmonic Compensation in Grid-Connected Applications," IEEE Trans. Power Electron., vol. 33, pp. 4868-4881, 2018.

[32] Z. Zou, et al., "Frequency-Adaptive Fractional-Order Repetitive Control of Shunt Active Power Filters," IEEE Trans. Ind. Electron., vol. 62, pp. 1659-1668, 2015.

[33] B.N. Abramovich and Y.A. Sychev, "The Control Algorithm for Active and Hybrid Correction Systems of Voltage and Current Waveforms," in Proceedings of the Dynamics of Systems, Mechanisms and Machines, Dynamics 2016, Omsk, Russian Federation, 2017.

[34] Y. V. Gulkov, A. V. Turysheva, A. V. Kopteva, "Research of grounding systems of electrical complexes in the conditions of permafrost soils," Proceedings of the 2019 IEEE Conference of Russian Young Researchers in Electrical and Electronic Engineering, ElConRus 2019, pp. 969-972, 2019.

[35] L. Wang, et al., "Hybrid Structure of Static VAR Compensator and Hybrid Active Power Filter (SVC//HAPF) for Medium-Voltage Heavy Loads Compensation," IEEE Trans. Ind. Electron., vol. 65, pp. 4432-4442, 2018.

[36] T.-L. Lee, et al., "Hybrid Active Filter with Variable Conductance for Harmonic Resonance Suppression in Industrial Power Systems," IEEE Trans. Ind. Electron., vol. 62, pp. 746-756, 2015.

[37] J. Solanki, et al., "Implementation of Hybrid Filter for 12-Pulse Thyristor Rectifier Supplying High-Current Variable-Voltage DC Load," IEEE Trans. Ind. Electron., vol. 62, pp. 4691-4701, 2015.

[38] B.N. Abramovich, et al., "Hybrid Harmonic Compensation Device Adapted for Variable Speed Drive System," IOP Conference Series: Earth and Environmental Science, vol. 87, no. 3, pp. 1-6, 2017.

[39] B. N. Abramovich, et al., "The Hybrid Correction System, Based on Active and Passive Filters for Harmonic Compensation in Networks of Oil Enterprises," Proceedings of 2018 International Multi-Conference on Industrial Engineering and Modern Technologies (FarEastCon), pp. 1-4, 2018.

[40] B. N. Abramovich, et al., "Efficiency Estimation of Hybrid Electrical Complex for Voltage and Current Waveform Correction in Power Systems of Oil Enterprises," Proceedings of 2019 IEEE Conference of Russian Young Researchers in Electrical and Electronic Engineering (EIConRus), pp. 397-402, 2019.

[41] S. Bosch, et al., "Predictive Current Control for an Active Power Filter with LCL-filter," IEEE Trans. Ind. Electron., vol. 65, pp. 4943-4952, 2018. 
[42] Y. Babkrani, A. Naddami, M. Hilal, "A Smart Cascaded H-Bridge Multilevel Inverter with an Optimized Modulation Techniques Increasing the Quality and Reducing Harmonics," International Journal of Power Electronics and Drive Systems (IJPEDS), vol. 10, no. 4, pp. 1852-1862, 2019.

[43] A. Safa, et al., "A Robust Control Algorithm for a Multifunctional Grid Tied Inverter to Enhance the Power Quality of a Microgrid under Unbalanced Conditions," Int. J. Electr. Power Energy Syst., vol. 100, pp. 253-264, 2018.

[44] E. Khoudry, et al., "Traveling Wave Based Fault Location for Power Transmission Lines using Morphological Filters and Clarke Modal Components," International Journal of Electrical and Computer Engineering (IJECE), vol. 10, no. 2, pp. 1122-1134, 2020.

[45] B. I. Yassine, A. Boumediene, "Renewable Energies Evaluation and Linking to Smart Grid," International Journal of Power Electronics and Drive Systems (IJPEDS), vol. 11, no. 1, pp. 107-118, 2020.

[46] O.O. Fares, "Log-Domain Electronically-Tuneable Fully Differential High Order Multi-Function Filter," International Journal of Electrical and Computer Engineering (IJECE), vol. 10, no. 2, pp. 1263-1272, 2020.

[47] G. R. Prudhvi Kumar, D. Sattianadan, K. Vijayakumar, "A Survey on Power Management Strategies of Hybrid Energy Systems in Microgrid," International Journal of Electrical and Computer Engineering (IJECE), vol. 10, no. 2, pp. 1667-1673, 2020.

[48] A. Subramanian, Santha K. R, "Review of Multiport Isolated Bidirectional Converter Interfacing Renewable and Energy Storage System," International Journal of Power Electronics and Drive Systems (IJPEDS), vol. 11, no. 1, pp. 466-467, 2020.

[49] T. Toumi, et al., "PV Integrated Single-Phase Dynamic Voltage Restorer for Sag Voltage, Voltage Fluctuations and Harmonics Compensation," International Journal of Power Electronics and Drive Systems (IJPEDS), vol. 11, no. 1, pp. 547-554, 2020.

[50] A. Chaithanakulwat, "Development of DC Voltage Control from Wind Turbines using Proportions and Integrals for Three-Phase Grid-Connected Inverters," International Journal of Electrical and Computer Engineering (IJECE), vol. 10, no. 2, pp. 1701-1711, 2020.

[51] A. Umar Lawan, et al., "Power Compensation for Vector-Based Current Control of a Modular Multilevel Converter (MMC) Based STATCOM," International Journal of Power Electronics and Drive Systems (IJPEDS), vol. 10, no. 4, pp. 1781-1796, 2019.

[52] S. Saidah, et al., "Modelling of three phase SVPWM AC-AC converter using unity power factor control," International Journal of Power Electronics and Drive Systems (IJPEDS), vol. 10, no. 4, pp. 1823-1832, 2019.

\section{BIOGRAPHIES OF AUTHORS}

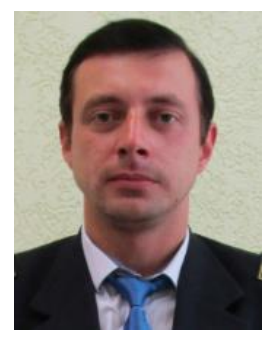

Yuriy Anatolievich Sychev received the Bachelor and Master degrees on electrical engineering at Saint-Petersburg Mining University, Saint-Petersburg, Russian Federation in 2005 and 2007 respectively. He also received the $\mathrm{PhD}$ degree on electrical complexes and systems at Saint-Petersburg Mining University in 2010. He is an Associated Professor of the Electromechanical Department in Saint-Petersburg Mining University. His current research area is the problems of power quality improvement in power supply systems of different structure, including centralized, distributed and combined power supply systems.

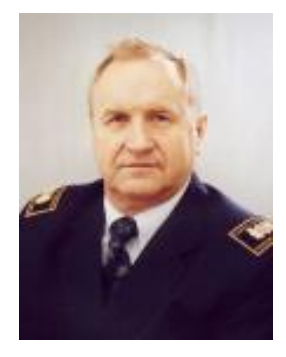

Boris Nikolaevich Abramovich graduated Saint-Petersburg Mining University, SaintPetersburg, Russian Federation as the specialist in mining electromechanic in 1961. $\mathrm{He}$ received the $\mathrm{PhD}$ degree and Doctor Tech. degree on electrical machines in 1971 and 1986 respectively. He is a Professor of the Electromechanical Department in Saint-Petersburg Mining University. His current research area is the problems of optimization and efficiency improvement of electrical complexes and systems of mineral resources enterprises.

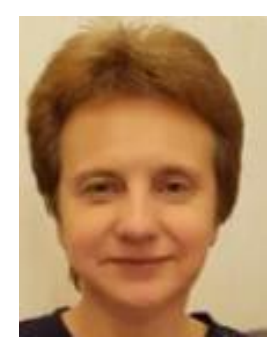

Veronika Borisovna Prokhorova graduated Saint-Petersburg Aerospace University, SaintPetersburg, Russian Federation as the specialist in automated control systems in 1986. She is a Deputy Director and Expert of the Tikhonov Moscow Institute of Electronics and Mathematics in Higher School of Economics. Her current research area is the problems of optimization and efficiency improvement of digital signal processing systems of electrical complexes and systems. 